Review

\title{
Plant Polygalacturonases Involved in Cell Elongation and Separation-The Same but Different?
}

\author{
Yashodar Babu and Martin Bayer * \\ Department of Cell Biology, Max Planck Institute for Developmental Biology, Spemannstrasse 35, \\ Tuebingen 72076, Germany; E-Mail: yashodar.babu@tuebingen.mpg.de
}

* Author to whom correspondence should be addressed; E-Mail: martin.bayer@tuebingen.mpg.de; Tel.: +49-7071-601-1305; Fax: +49-7071-601-1308.

External Editor: Philip J. Harris

Received: 10 October 2014; in revised form: 25 November 2014 / Accepted: 28 November 2014 / Published: 9 December 2014

\begin{abstract}
Plant cells are surrounded by the primary cell wall, a rigid framework that needs to be modified in order to allow cell growth. Recent data suggest that in addition to the cellulose-hemicellulose network, the pectin matrix plays a critical role in determining the elasticity of the primary cell wall. Polygalacturonases are key homogalacturonan-hydrolyzing enzymes that function in a wide range of developmental processes. In this review, we present recent progress in understanding the role of polygalacturonases during cell elongation and separation. In discussing the specificities and possible redundancies of polygalacturonases, we focus particularly on newly discovered Arabidopsis mutants that have measurable loss-of-function phenotypes. However, data from other species are included when necessary.
\end{abstract}

Keywords: polygalacturonase; pectin; cell wall; cell elongation; genetic redundancy

\section{Introduction}

In plants, cells are surrounded by a rigid cell wall and are, therefore, fixed in their relative position. As a consequence, the overall shape of the plant body is created by a tightly controlled interplay of cell division and anisotropic cell expansion. The driving force for cell expansion is turgor pressure and it requires controlled relaxation of the cell wall while maintaining cellular integrity [1]. The high osmotic pressure inside the cell, ranging from 0.3 to $1.2 \mathrm{MPa}$ in the case of Arabidopsis thaliana, makes this a 
non-trivial task [2]. Secondary cell-wall material can fortify cell walls after cell elongation has ceased but it is the primary cell wall of meristematic and elongating cells that needs to be modified to control the shape of the plant body [3].

The typical primary cell wall is a complex matrix composed of polysaccharides, a variety of proteins, and phenolics with cellulose, hemicelluloses, and pectin almost equally representing the main polysaccharide content [4]. A major constituent of this composite network is cellulose, a linear $\beta$-1,4-glucan, which co-crystalizes with other cellulose polymers into microfibrils, long, rigid fibers that can wind around the cell many times [1,5]. In seed plants (spermatophytes), the most abundant hemicelluloses in primary cell walls are usually xyloglucans (XG). However, the commelinid monocots, which include the grass family, are an exception, as in this group glucuronorarabinoxylans generally predominate [6]. Hemicelluloses are thought to cross-link cellulose microfibrils, thereby creating a rigid network while at the same time enforcing certain spacing between microfibrils to adjust primary cell wall flexibility $[1,6]$.

In this view, the cellulose-xyloglucan network is the main structural component with load-bearing properties while pectin acts as filler matrix similar to composite materials of fiber-reinforced polymers. The extensibility of this network is modified by wall-loosening expansins, which are thought to act on the non-covalent interactions between cellulose microfibrils, as well as XG endo-transglycosylases [1].

This traditional model has recently been challenged by data that suggest that only a minor portion of $\mathrm{XG}$ is bound directly to cellulose [7] and that pectin displays load-bearing properties in the absence of $\mathrm{XG}$. Therefore the pectin matrix seems to play a more important role in determining the extensibility of the primary cell wall than previously recognized [7-9].

Pectin consists of complex high molecular weight polysaccharides that can form hydrated gels. It can be classified into domains of homogalacturonan (HG), rhamnogalacturonan I (RG I) and RG II, and xylogalacturonan depending on the backbone and the degree of branching. The most abundant pectin form is homogalacturonan, a linear polymer of $\alpha-1,4$-linked D-galacturonic acid [10]. It is synthesized in the cis-Golgi by galacturonosyltransferases (GAUTs) and usually highly methyl-esterified by pectin methyltransferases (PMTs) and to lesser degree acetylated by pectin acetyltransferases (PATs) [11]. The degree of methylesterification and acetylation plays a critical role in determining the stiffness of the cell wall since negative charges on the HG backbone can cross-link HG polymers via calcium ions [12]. Pectin methylesterases (PMEs) can hydrolyze methylester bonds and therefore have the potential to increase the degree of $\mathrm{HG}$ cross-linking. Interestingly, it was shown that ectopic, ubiquitous expression of PME inhibitors leads to stiffening of cell walls while ectopic expression of PMEs leads to softening [13,14]. This might be explained by competition between different HG sites for binding of calcium ions where newly de-esterified sites lead to the disruption of existing, load-bearing cross-links [9]. On the other hand, the de-esterification might also allow hydrolyzing enzymes like polygalacturonases (PGs) to act on the HG chain leading to softening of the cell wall [12]. Since the amount, structure and modification of pectin influences the physical properties of the cell wall, growth control most likely requires fine-tuning of all these variables. A more detailed description of pectin biosynthesis and structure as well as its modifications during cell growth can be found in the following comprehensive reviews $[11,12,15-17]$. 


\section{Polygalacturonases}

Polygalacturonases belong to the glycosyl hydrolase family 28 and are key HG hydrolyzing enzymes that have been implicated with a wide range of plant developmental processes such as cell elongation, organ abscission, fruit ripening, microspore release, and pollen tube growth [18]. Plant PG genes belong to large gene families and their expansion and diversification can be attributed to whole genome and segmental duplications in association with gene loss, as well as intron gain and (more predominantly) intron loss events [19,20]. Phylogenetic analysis of PG gene structure in Arabidopsis, rice, and other plant species reveals five distinct clades of PG genes which can be further divided into subclades indicating the occurrence of at least four ancestral PG genes before the divergence of monocots and dicots. While sequences from different clades are relatively divergent, they are rather conserved within a clade and tandem-duplicated genes generally fall into the same subclade [19-22]. Depending on their mode of action, endo- and exo-polygalacturonases can be distinguished [23]. Endo-PGs hydrolyze the $\mathrm{HG}$ polymer at random sites but require at least four consecutive GalA residues of the HG chain to be de-methylesterified [24,25]. Thus, the methylation pattern of the HG chains directly influences possible endo-PG-mediated HG cleavage. Endo-PG activity might lead to complete hydrolysis of pectin polymers and has therefore the potential to cause rapid cell elongation or even cell separation [12,26].

Exo-PGs on the other hand attack the free ends of de-methylesterified HG polymers and thereby reduce the overall polymer length. It has been speculated that the resulting modification of the pectin matrix might be subtler than the random cleavage by endo-PGs and might, therefore, be used to fine-tune the extensibility of the primary cell wall [27].

\section{Polygalacturonases Involved in Fruit Ripening and Cell Separation}

Early on, polygalacturonases were isolated from ripening fruits which implied a role in pectin degradation for tissue softening [28]. In a pioneer work in tomato, down-regulation of polygalacturonase expression by an anti-sense construct lead to decreased de-polymerization of solubilized pectins and increased storage-life of ripe fruits although there was no measureable effect on fruit softening [29,30]. Silencing of PG expression in apple and strawberry on the other hand increased the firmness of the ripe fruit significantly but did not change other ripening parameters. It could be shown that in these transgenic plants, ionically and covalently bound pectin exhibits a lower degree of de-polymerization. Microscopic analysis of transgenic fruits revealed smaller intra-cellular spaces and more cellular adhesion [31-33]. This is in agreement with earlier reports demonstrating that pectin degradation by PGs also plays a central role in cell separation in abscission events and dehiscence zones [34-36]. In apples, constitutive expression of the fruit-specific MdPG1 gene resulted in a range of novel developmental phenotypes including premature leaf shedding due to reduced cell adhesion in abscission zones, malformed leaves and malfunctioning stomata. As a consequence of the strong constitutive expression of MdPG1 in transgenic apple trees, a decrease of the average molecular weight of pectin chains could be demonstrated [37]. In rice, over-expression of OsBURP16, the non-catalytic PG1 $\beta$-subunit of the polygalacturonase PG1, reduced cell adhesion in leaves and pectin content [38]. Together these data support the involvement of PGs in cell separation events in plants. 
Many polygalacturonase genes are highly expressed in reproductive tissue [21], and for some, their involvement in cell separation events could be demonstrated by loss-of-function phenotypes: The endo-PG QUARTET3 (QRT3) functions in degrading the pollen mother cell wall during microsporogenesis and thus enables the release of unicellular microspores [39]. ARABIDOPSIS DEHISCENCE ZONE POLYGALACTURONASE1 (ADPG1), ADPG2, and QRT2 were reported to act in a redundant manner in anther dehiscence while ADPG2 and QRT2 function partially redundant in floral organ abscission [40].

\section{Polygalacturonases Involved in Cell Expansion}

The previously mentioned examples of polygalacturonases involved in fruit ripening and cell separation might lead to the conclusion that the primary role of endo-PGs is the more or less complete breakdown of the pectin matrix in terminal developmental situations like tissue softening, abscission, or dehiscence. This is clearly not the whole story, since, recently, the endo-PG POLYGALACTURONASE INVOLVED IN EXPANSION1 (PGX1) was shown to be involved in hypocotyl elongation and floral patterning [41]. Furthermore, in vivo assays for pectin-degrading enzymes suggested that during cotyledon expansion in cotton endo-PG and exo-PG activity could both be detected. Interestingly, their appearance differed temporally during cell elongation with high endo-PG activity at an early phase, followed by an increase of exo-PG activity during a later phase when endo-PG activity decreased [26]. This implies a scenario where different pectin hydrolyzing enzymes might act on the same substrate but in a consecutive manner.

The pectinase LeXPG1 was isolated from tomato seed protein extracts and gene expression was detected in the embryonic root, the developing vasculature as well as the embryo-surrounding endosperm. Based on this expression pattern, it was suggested that LeXPG1 might play a role in cell elongation as well as tissue softening in the embryo and the endosperm, respectively. Interestingly, LeXPG1 displays calcium-dependent exo-PG activity [42]. Furthermore, exo-polygalacturonase activity had been observed during abscission events in citrus explants before [43]. Endo-PGs and exo-PGs seem to be both involved in cell elongation as well as cell separation events. Therefore, their enzymatic activity does not directly correlate with one or the other process but rather a combination of both activities seems to be necessary in both events. Hence, it is tempting to speculate if cell elongation and cell separation in principal rely on identical pectin modifications.

The Arabidopsis genome contains 69 PG genes [35,44]. Several of these arose from tandem duplications and belong to the same phylogenetic subclade [21]. Intuitively, one would speculate that these tandem-duplicated genes might act in a redundant manner if the expression pattern of these genes did not diverge. Only for a handful of PG genes is there direct evidence for their function during development, based on loss-of-function phenotypes. For many other Arabidopsis PG genes, the lack of an obvious loss-of-function phenotype might indeed be a result of genetic redundancy [18].

Recent findings might shed some further light on this situation: Cell elongation defects were reported in embryos of the Arabidopsis nimna (nma) mutant [45]. NMA codes for a putative exo-polygalacturonase and is preferentially expressed in reproductive tissue. Cells of nma mutant embryos fail to elongate as early as the zygote stage and severe cell elongation defects can be further observed in the suspensor while cells of the embryo-proper seem to recover from their defects at later stages of embryo 
development (Figure 1) [45]. This might indicate that other polygalacturonases can take over NMA function in the embryo-proper.

Figure 1. Embryonic phenotype of $n m a$ mutants. Suspensor cells in $n m a-1^{-/}$embryos show reduced cell elongation compared to wild-type. The embryo proper is false-colored in green, suspensor cells are false-colored in yellow. Scale bar: $20 \mu \mathrm{m}$.
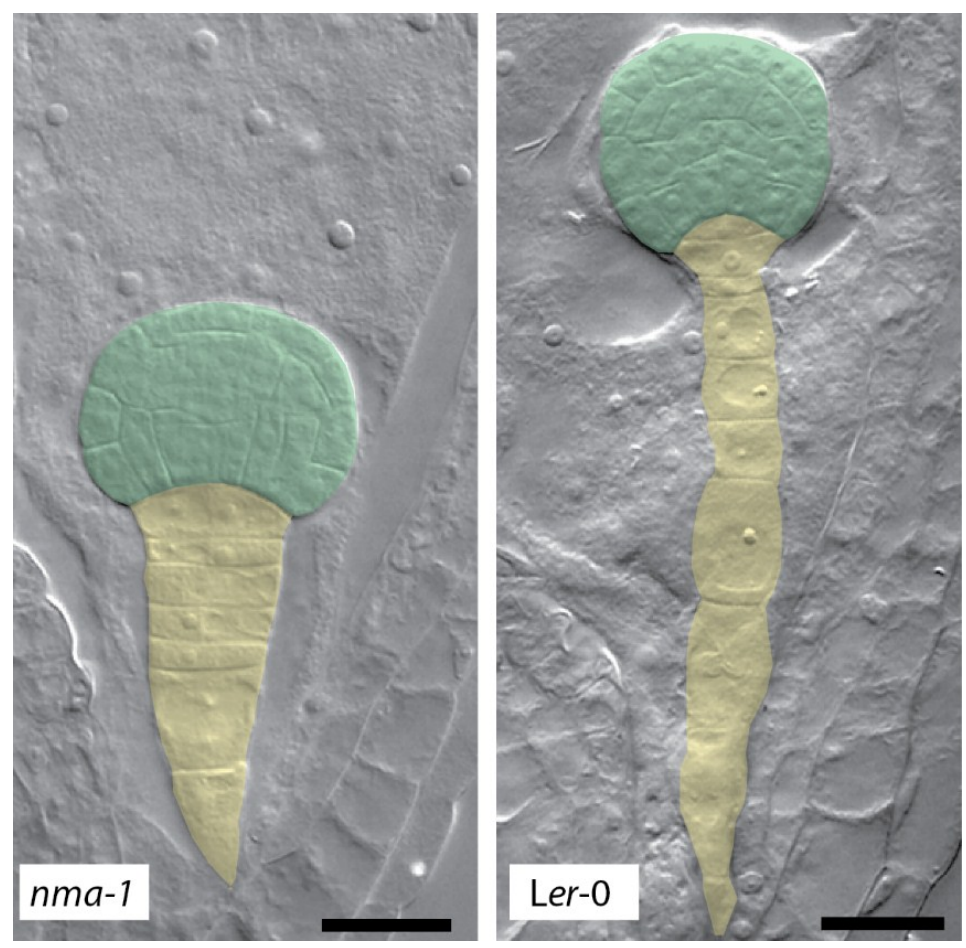

Peptides from five PGs including NMA were found to be present in cell wall fractions of 5 day-old etiolated hypocotyls of Arabidopsis [46]. While NMA is obviously present in elongating hypocotyls, the nma mutation does not seem to have any measurable effect on hypocotyl length [45]. It appears that other PGs are able to compensate for the loss of NMA activity in this case. For the embryonic suspensor, the situation seems to be different: While there are several closely related PG genes expressed in the suspensor of globular stage embryos according to published microarray data (Figure 2) [47], the strong cell-elongation defects observed in nma mutants indicate that none of these can fulfill NMA function [45]. The reason for this might be different temporal expression, sub-cellular localization, enzyme activity, or substrate specificity.

A similar situation was observed for the closely related $A D P G 1, A D P G 2$, and $Q R T 2$ genes (Figure 2) [40]. Loss of all three genes causes an impaired pod shatter phenotype and compromises anther dehiscence. While the $p A D P G 1: \because A D P G 1$ transgene was able to fully complement the pod shatter defects of the triple mutant, QRT2 and the closely related PG gene At1g48100 failed to do so when expressed under the $A D P G 1$ promoter [40]. Again, this would argue for a distinct function of these proteins in the cell separation process possibly caused by different enzymatic activity or substrate preference.

Expression analysis of three closely related tomato PG genes (TAPGl, TAPG2, and TAPG4) indicates temporal regulation during leaf and flower abscission. The temporal expression pattern of these genes suggests that they might act consecutively to fulfill a stepwise modification of the pectin matrix [48]. 
Figure 2. Phylogeny and expression values of $N M A$ - and $Q R T 2$-related polygalacturonase genes. (A) Phylogenetic tree of NMA- and QRT2-related polygalacturonases. Phylogeny was created with protein sequences of two sub-clades A1a and A14 [21] using neighbour-joining with bootstrap values of 100 [49]. Some of the PGs mentioned in this review (Medicago sativa PG3, Solanum lycopersicum XPG1 and a bacterial exo-PG from Yersinia enterocolitica) were also included as outgroups. Scale bar represents amino acid substitutions per site; (B) Mean expression values of selected Arabidopsis polygalacturonase genes closely related to NMA in the embryo and suspensor based on publicly available microarray data [47].

A

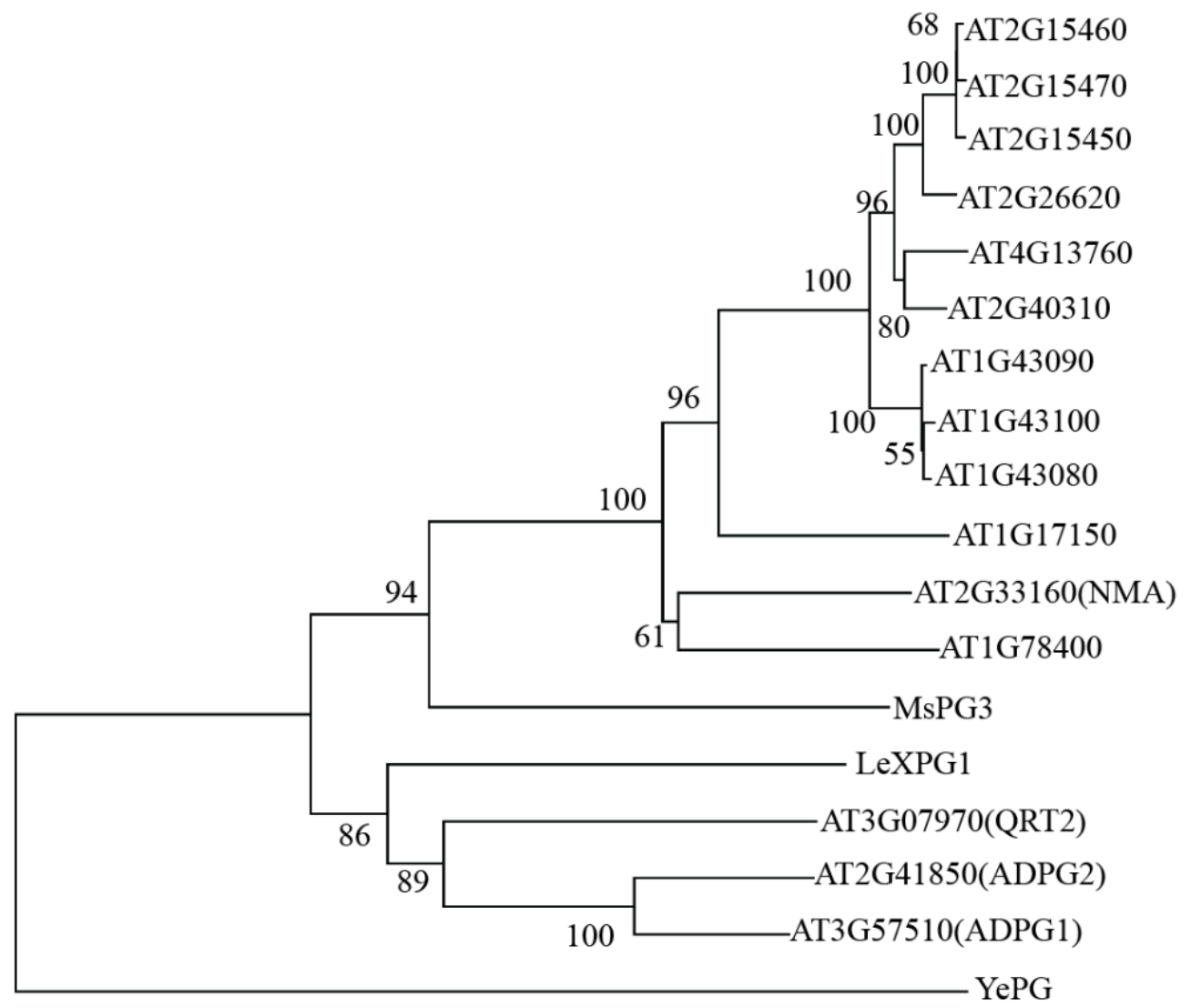

B

0.2

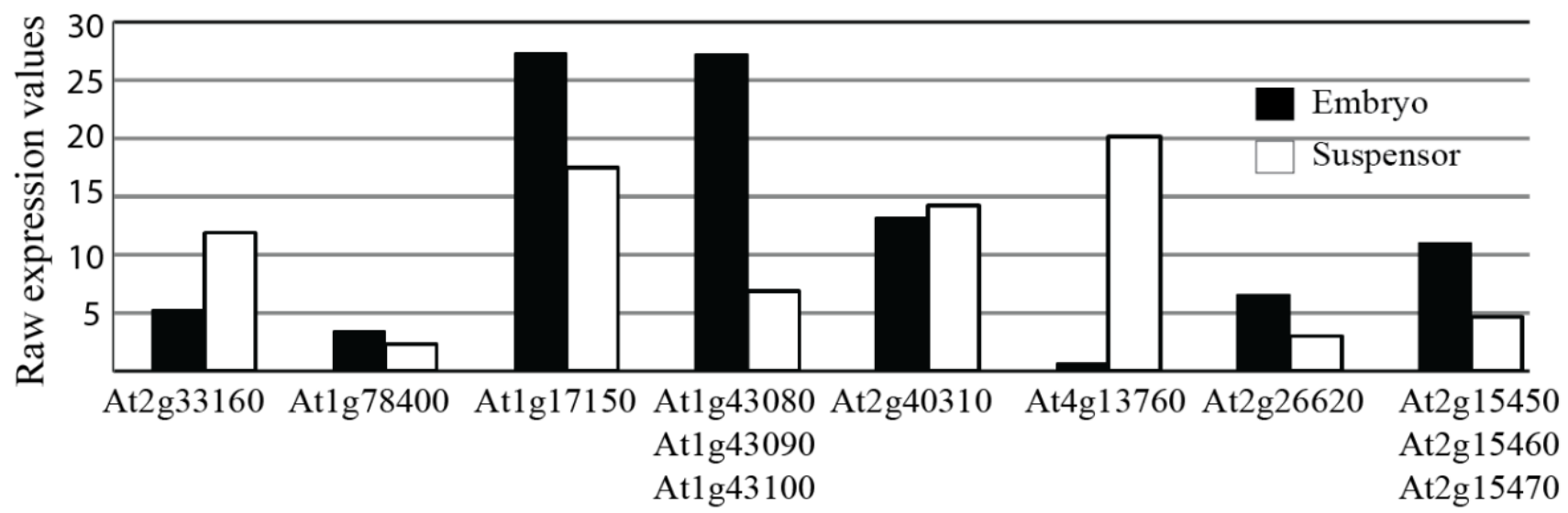

Gene Locus 


\section{Perspectives}

Pectin plays a central role in determining the physicochemical properties of the primary cell wall. Modifications of the pectin matrix are thus elementary for cell elongation by determining the extensibility of the cell wall. The degree of methyl-esterification is one important aspect that seems to be tightly regulated, but recent data emphasizes the importance of pectin-hydrolyzing polygalacturonases in cell elongation processes [41,45]. The temporally regulated activity of endo-as well as exo-PGs seems essential for both cell elongation and cell separation processes. To what degree the vast number of PG genes in the Arabidopsis genome reflects genetic redundancy or displays the need for a high number of specific enzymes in these cell wall processes is still unclear. With recently described Arabidopsis mutants like $n m a$ or $p g x l$, which show obvious and quantifiable loss-of-function phenotypes, this question can now be addressed. Promoter-swap and complementation experiments are powerful tools to support the biochemical analysis of these proteins. Complementation experiments with endo- and exo-PGs will allow a better understanding to what degree these enzymes are functionally redundant or are involved in separate non-exchangeable steps in pectin modification during cell elongation processes.

The active site in PG proteins is well conserved but substrate recognition motifs are not well understood [23]. In vivo complementation assays along with biochemical studies guided by protein-structure data might help unraveling specific modes of substrate recognition.

Technical advances have greatly helped our understanding of the primary cell wall composition [5,50-52]. Studying the effect of well-characterized PGs might indirectly give further insight in cell wall composition and the structure and modifications of the pectin matrix.

Furthermore, with the recent advances in genome-editing tools, like the CRISPR/Cas9 system and their application in plant biology, the study of many tandem-duplicated PG genes is now technically possible $[53,54]$.

Understanding the substrate-specificity and the nature of the pectin modification carried out by specific polygalacturonases will not only increase our understanding of plant cell wall biology during cell elongation but will also be valuable for their use in commercial products and technical processes like biofuel production.

\section{Acknowledgments}

We apologize to our colleagues whose publications could not be included in this short review. We thank Cameron Lee, Thomas Musielak, and Daniel Slane for critical reading of the manuscript. Research in our lab is supported by the German Science Foundation (DFG, SFB1101) and the Max Planck Society.

\section{Author Contributions}

Yashodar Babu and Martin Bayer prepared the figures and wrote the manuscript.

\section{Conflicts of Interest}

The authors declare no conflict of interest. 


\section{References}

1. Cosgrove, D.J. Growth of the plant cell wall. Nat. Rev. Mol. Cell Biol. 2005, 6, 850-861.

2. Forouzesh, E.; Goel, A.; Mackenzie, S.A.; Turner, J.A. In vivo extraction of Arabidopsis cell turgor pressure using nanoindentation in conjunction with finite element modeling. Plant J. 2013, 73, 509-520.

3. Zhong, R.; Ye, Z.H. Regulation of cell wall biosynthesis. Curr. Opin. Plant Biol. 2007, 10, 564-572.

4. Mcneil, M.; Darvill, A.G.; Fry, S.C.; Albersheim, P. Structure and function of the primary-cell walls of plants. Annu. Rev. Biochem. 1984, 53, 625-663.

5. Nishiyama, Y.; Langan, P.; Chanzy, H. Crystal structure and hydrogen-bonding system in cellulose Ibeta from synchrotron X-ray and neutron fiber diffraction. J. Am. Chem. Soc. 2002, 124, 9074-9082.

6. Scheller, H.V.; Ulvskov, P. Hemicelluloses. Annu. Rev. Plant Biol. 2010, 61, 263-289.

7. Dick-Perez, M.; Zhang, Y.; Hayes, J.; Salazar, A.; Zabotina, O.A.; Hong, M. Structure and interactions of plant cell-wall polysaccharides by two- and three-dimensional magic-angle-spinning solid-state NMR. Biochemistry 2011, 50, 989-1000.

8. Park, Y.B.; Cosgrove, D.J. Changes in cell wall biomechanical properties in the xyloglucan-deficient xxt1/xxt2 mutant of Arabidopsis. Plant Physiol. 2012, 158, 465-475.

9. Peaucelle, A.; Braybrook, S.; Hofte, H. Cell wall mechanics and growth control in plants: The role of pectins revisited. Front. Plant Sci. 2012, 3, 121.

10. Ridley, B.L.; O’Neill, M.A.; Mohnen, D. Pectins: Structure, biosynthesis, and oligogalacturonide-related signaling. Phytochemistry 2001, 57, 929-967.

11. Atmodjo, M.A.; Hao, Z.; Mohnen, D. Evolving views of pectin biosynthesis. Annu. Rev. Plant Biol. 2013, 64, 747-779.

12. Senechal, F.; Wattier, C.; Rusterucci, C.; Pelloux, J. Homogalacturonan-modifying enzymes: Structure, expression, and roles in plants. J. Exp. Bot. 2014, 65, 5125-5160.

13. Peaucelle, A.; Louvet, R.; Johansen, J.N.; Hofte, H.; Laufs, P.; Pelloux, J.; Mouille, G. Arabidopsis phyllotaxis is controlled by the methyl-esterification status of cell-wall pectins. Curr. Biol. 2008, 18, 1943-1948.

14. Peaucelle, A.; Braybrook, S.A.; le Guillou, L.; Bron, E.; Kuhlemeier, C.; Hofte, H. Pectin-induced changes in cell wall mechanics underlie organ initiation in Arabidopsis. Curr. Biol. 2011, 21, $1720-1726$.

15. Wolf, S.; Greiner, S. Growth control by cell wall pectins. Protoplasma 2012, 249, 169-175.

16. Wolf, S.; Mouille, G.; Pelloux, J. Homogalacturonan methyl-esterification and plant development. Mol. Plant 2009, 2, 851-860.

17. Willats, W.G.; McCartney, L.; Mackie, W.; Knox, J.P. Pectin: Cell biology and prospects for functional analysis. Plant Mol. Biol. 2001, 47, 9-27.

18. Hadfield, K.A.; Bennett, A.B. Polygalacturonases: Many genes in search of a function. Plant Physiol. 1998, 117, 337-343.

19. Torki, M.; Mandaron, P.; Mache, R.; Falconet, D. Characterization of a ubiquitous expressed gene family encoding polygalacturonase in Arabidopsis thaliana. Gene 2000, 242, 427-436. 
20. Park, K.C.; Kwon, S.J.; Kim, P.H.; Bureau, T.; Kim, N.S. Gene structure dynamics and divergence of the polygalacturonase gene family of plants and fungus. Genome 2008, 51, 30-40.

21. Kim, J.; Shiu, S.H.; Thoma, S.; Li, W.H.; Patterson, S.E. Patterns of expansion and expression divergence in the plant polygalacturonase gene family. Genome Biol. 2006, 7, R87.

22. Park, K.C.; Kwon, S.J.; Kim, N.S. Intron loss mediated structural dynamics and functional differentiation of the polygalacturonase gene family in land plants. Genes Genomics 2010, 32, 570-577.

23. Markovic, O.; Janecek, S. Pectin degrading glycoside hydrolases of family 28: Sequence-structural features, specificities and evolution. Protein Eng. 2001, 14, 615-631.

24. Protsenko, M.A.; Buza, N.L.; Krinitsyna, A.A.; Bulantseva, E.A.; Korableva, N.P. Polygalacturonaseinhibiting protein is a structural component of plant cell wall. Biochemistry (Mosc.) 2008, 73, 1053-1062.

25. Clausen, M.H.; Willats, W.G.T.; Knox, J.P. Synthetic methyl hexagalacturonate hapten inhibitors of antihomogalacturonan monoclonal antibodies LM7, JIM5 and JIM7. Carbohydr. Res. 2003, 338, 1797-1800.

26. Zhang, Z.Q.; Pierce, M.L.; Mort, A.J. Changes in homogalacturonans and enzymes degrading them during cotton cotyledon expansion. Phytochemistry 2007, 68, 1094-1103.

27. Abbott, D.W.; Boraston, A.B. The structural basis for exopolygalacturonase activity in a family 28 glycoside hydrolase. J. Mol. Biol. 2007, 368, 1215-1222.

28. Pressey, R.; Hinton, D.M.; Avants, J.K. Development of Polygalacturonase Activity and Solubilization of Pectin in Peaches during Ripening. J. Food Sci. 1971, 36, 1070-1073.

29. Smith, C.J.; Watson, C.F.; Morris, P.C.; Bird, C.R.; Seymour, G.B.; Gray, J.E.; Arnold, C.; Tucker, G.A.; Schuch, W.; Harding, S.; et al. Inheritance and effect on ripening of antisense polygalacturonase genes in transgenic tomatoes. Plant Mol. Biol. 1990, 14, 369-379.

30. Smith, C.J.S.; Watson, C.F.; Ray, J.; Bird, C.R.; Morris, P.C.; Schuch, W.; Grierson, D. Antisense RNA inhibition of polygalacturonase gene-expression in transgenic tomatoes. Nature 1988, 334, 724-726.

31. Atkinson, R.G.; Sutherland, P.W.; Johnston, S.L.; Gunaseelan, K.; Hallett, I.C.; Mitra, D.; Brummell, D.A.; Schroder, R.; Johnston, J.W.; Schaffer, R.J. Down-regulation of POLYGALACTURONASE1 alters firmness, tensile strength and water loss in apple (Malus $x$ domestica) fruit. BMC Plant Biol. 2012, 12, 129.

32. Pose, S.; Paniagua, C.; Cifuentes, M.; Blanco-Portales, R.; Quesada, M.A.; Mercado, J.A. Insights into the effects of polygalacturonase FaPG1 gene silencing on pectin matrix disassembly, enhanced tissue integrity, and firmness in ripe strawberry fruits. J. Exp. Bot. 2013, 64, 3803-3815.

33. Quesada, M.A.; Blanco-Portales, R.; Pose, S.; Garcia-Gago, J.A.; Jimenez-Bermudez, S.; Munoz-Serrano, A.; Caballero, J.L.; Pliego-Alfaro, F.; Mercado, J.A.; Munoz-Blanco, J. Antisense down-regulation of the FaPG1 gene reveals an unexpected central role for polygalacturonase in strawberry fruit softening. Plant Physiol. 2009, 150, 1022-1032.

34. Tucker, G.A.; Schindler, C.B.; Roberts, J.A. Flower abscission in mutant tomato plants. Planta 1984, 160, 164-167.

35. Gonzalez-Carranza, Z.H.; Elliott, K.A.; Roberts, J.A. Expression of polygalacturonases and evidence to support their role during cell separation processes in Arabidopsis thaliana. J. Exp. Bot. 2007, 58, 3719-3730. 
36. Petersen, M.; Sander, L.; Child, R.; van Onckelen, H.; Ulvskov, P.; Borkhardt, B. Isolation and characterisation of a pod dehiscence zone-specific polygalacturonase from Brassica napus. Plant Mol. Biol. 1996, 31, 517-527.

37. Atkinson, R.G.; Schroder, R.; Hallett, I.C.; Cohen, D.; MacRae, E.A. Overexpression of polygalacturonase in transgenic apple trees leads to a range of novel phenotypes involving changes in cell adhesion. Plant Physiol. 2002, 129, 122-133.

38. Liu, H.; Ma, Y.; Chen, N.; Guo, S.; Liu, H.; Guo, X.; Chong, K.; Xu, Y. Overexpression of stress-inducible OsBURP16, the beta subunit of polygalacturonase 1, decreases pectin content and cell adhesion and increases abiotic stress sensitivity in rice. Plant Cell Environ. 2014, 37, 1144-1158.

39. Rhee, S.Y.; Osborne, E.; Poindexter, P.D.; Somerville, C.R. Microspore separation in the quartet 3 mutants of Arabidopsis is impaired by a defect in a developmentally regulated polygalacturonase required for pollen mother cell wall degradation. Plant Physiol. 2003, 133, 1170-1180.

40. Ogawa, M.; Kay, P.; Wilson, S.; Swain, S.M. ARABIDOPSIS DEHISCENCE ZONE POLYGALACTURONASE1 (ADPG1), ADPG2, and QUARTET2 are Polygalacturonases required for cell separation during reproductive development in Arabidopsis. Plant Cell 2009, 21, 216-233.

41. Xiao, C.; Somerville, C.; Anderson, C.T. POLYGALACTURONASE INVOLVED IN EXPANSION1 functions in cell elongation and flower development in Arabidopsis. Plant Cell 2014, 26, 1018-1035.

42. Sitrit, Y.; Hadfield, K.A.; Bennett, A.B.; Bradford, K.J.; Downie, A.B. Expression of a polygalacturonase associated with tomato seed germination. Plant Physiol. 1999, 121, 419-428.

43. Riov, J. A polygalacturonase from citrus leaf explants: role in abscission. Plant Physiol. 1974, 53, 312-316.

44. Cao, J. The pectin lyases in Arabidopsis thaliana: Evolution, selection and expression profiles. PLoS One 2012, 7, e46944.

45. Babu, Y.; Musielak, T.; Henschen, A.; Bayer, M. Suspensor length determines developmental progression of the embryo in Arabidopsis. Plant Physiology 2013, 162, 1448-1458.

46. Irshad, M.; Canut, H.; Borderies, G.; Pont-Lezica, R.; Jamet, E. A new picture of cell wall protein dynamics in elongating cells of Arabidopsis thaliana: Confirmed actors and newcomers. BMC Plant Biol. 2008, 8, 94.

47. Le, B.H.; Cheng, C.; Bui, A.Q.; Wagmaister, J.A.; Henry, K.F.; Pelletier, J.; Kwong, L.; Belmonte, M.; Kirkbride, R.; Horvath, S.; et al. Global analysis of gene activity during Arabidopsis seed development and identification of seed-specific transcription factors. Proc. Natl. Acad. Sci. USA 2010, 107, 8063-8070.

48. Kalaitzis, P.; Solomos, T.; Tucker, M.L. Three different polygalacturonases are expressed in tomato leaf and flower abscission, each with a different temporal expression pattern. Plant Physiol. 1997, 113, 1303-1308.

49. Tamura, K.; Stecher, G.; Peterson, D.; Filipski, A.; Kumar, S. MEGA6: Molecular evolutionary genetics analysis version 6.0. Mol. Biol. Evol. 2013, 30, 2725-2729.

50. Somerville, C.; Bauer, S.; Brininstool, G.; Facette, M.; Hamann, T.; Milne, J.; Osborne, E.; Paredez, A.; Persson, S.; Raab, T.; et al. Toward a systems approach to understanding plant cell walls. Science 2004, 306, 2206-2211. 
51. Burgert, I.; Keplinger, T. Plant micro- and nanomechanics: Experimental techniques for plant cell-wall analysis. J. Exp. Bot. 2013, 64, 4635-4649.

52. Knox, J.P.; Linstead, P.J.; King, J.; Cooper, C.; Roberts, K. Pectin esterification is spatially regulated both within cell walls and between developing tissues of root apices. Planta 1990, 181, 512-521.

53. Shan, Q.; Wang, Y.; Li, J.; Zhang, Y.; Chen, K.; Liang, Z.; Zhang, K.; Liu, J.; Xi, J.J.; Qiu, J.L.; et al. Targeted genome modification of crop plants using a CRISPR-Cas system. Nat. Biotechnol. 2013, 31, 686-688.

54. Feng, Z.; Mao, Y.; Xu, N.; Zhang, B.; Wei, P.; Yang, D.L.; Wang, Z.; Zhang, Z.; Zheng, R.; Yang, L.; et al. Multigeneration analysis reveals the inheritance, specificity, and patterns of CRISPR/Cas-induced gene modifications in Arabidopsis. Proc. Natl. Acad. Sci. USA 2014, 111, 4632-4637.

(C) 2014 by the authors; licensee MDPI, Basel, Switzerland. This article is an open access article distributed under the terms and conditions of the Creative Commons Attribution license (http://creativecommons.org/licenses/by/4.0/). 